\title{
Research on Fire Protection Methods of Cables in Substations
}

\author{
Kai Xue ${ }^{1, *}$,Zheng Wang ${ }^{1}$, Chunguang Ren ${ }^{1}$,Huixia Wang ${ }^{1}$, and Feng Li $^{1}$ \\ ${ }^{1}$ Economic and Electrical Research Institute of Shanxi Electrical Power Company of SGCC, Taiyuan, China
}

\begin{abstract}
The normal operation of the substation is inseparable from the important guarantee of the cable. The cables in the substation are not only widely distributed, but also the cables are flammable and spread easily after fire. Once a cable catches fire, the consequences will be disastrous. Therefore, how to fire the cable becomes an important task for the power system. Many engineers and technicians continue to analyze and study the causes of cable fires, but cable fire accidents still occur from time to time. In order to solve the problem of cable fire protection and existing problems, the article combines actual research and analysis, and gives the most effective and safe cable fire protection method.
\end{abstract}

\section{Introduction}

This thesis mainly studies the characteristics of substation cable fire protection, as well as the design concept and design key technologies. A detailed analysis of a substation cable fire protection design scheme is carried out, and safe and feasible methods of substation cable fire protection are given.

\section{Operating characteristics of substation cables}

Cables are spread throughout the entire substation and their main function is to transmit energy and signals. The transmission of energy is realized by AC and DC power cables of various voltage levels. The transmission signal is realized by the control cable and the communication cable. Communication cables include high-frequency communication cables, relay protection device communication network cables and optical cables [1].

There are two ways of laying cables: direct laying and laying with protective materials. Direct laying is generally laid directly in the air; laying with protective materials can be divided into laying through pipes, laying in tanks and boxes, laying in cable trenches, laying on shelf support and laying in tunnels, etc. The former is less used and the latter is widely used in substations. Among them, cable trench laying, layer frame laying and tunnel laying are determined by the actual construction conditions. The monitoring of cables during operation generally adopts the method of daily inspection by inspectors, and the cables laid on the cable layer are carried out through industrial TV.

Cables are an important carrier for power transmission and information transmission in substations. However, due to the single monitoring measures for the safe operation of cables, day and night monitoring cannot be carried out throughout the station. For accidents such as fires or during operation of cables The hidden dangers of insecurity cannot be controlled in a timely and effective manner.

Therefore, the safe operation of substations will be seriously affected. In order to prevent problems before they occur, more effective fire protection measures should be taken for the cables in operation.

Because cable heads are usually hand-made on site, due to site conditions and the dispersion of hand-made, generally cable heads are the weak link of cable insulation. Therefore, strengthening the monitoring and management of cable heads is an important part of cable fire protection. Try not to put the cable terminal in the cable trench, cable tunnel, cable trough box, or cable interlayer. For those power cable terminal heads and intermediate joints placed in cable trenches, cable tunnels, cable trays, and cable interlayers, they must be registered, and the temperature should be measured regularly with a far-infrared thermometer. If abnormal temperature rise of the cable head is found, Should exit operation in time to avoid the cable head catching fire during operation.

In addition, there should be fire-resistant barriers for the cable terminal heads and intermediate joints to ensure that the cable head will not ignite other adjacent cables if it catches fire.

\section{Strengthen cable design management}

Choose the cable reasonably according to the load, and the cable length and capacity should be surplus. The design of the cable trench should fully consider the number of cables and their own quality requirements, create a good operating environment for the cable, and avoid accelerating the aging and damage of the cable insulation due to the harsh operating environment.

The cable trench should be made of cement and have good drainage facilities, such as shallow drainage ditches

*orresponding author:448404163@qq.com 
and water collection wells, and effective drainage to prevent water accumulation, water seepage, and water leakage, and keep the internal dry bath to prevent water, corrosive gases, and liquids from entering cable trench. There must be complete anti-rodent intrusion facilities to prevent animals from destroying the cable insulation and causing fire accidents [2].

Cable brackets should be installed in the cable trenches, the cables are placed overhead and layered, and the cable trench cover is designed with high standards to meet the strength requirements to help keep the cover intact during long-term operation. No other equipment that may cause fire should be placed in the mezzanine, tunnel, and shaft of the centralized control room, and the cables should be arranged neatly and clearly, leaving enough patrol channels.

Fire-proof and flame-retardant means: effective flame-retardant sealing should be adopted in the holes leading to the centralized control room, cables, cabinets, and trays; fire-resistant tapes should be added on both sides of the power cable middle head box and adjacent sections; outdoor high voltage The cable trench cover near the current transformer and voltage transformer should be sealed.

\section{Research on Cable Laying Design Method}

\subsection{Cabling}

The three-dimensional design and application of power transmission and transformation engineering, as the main means to realize the ubiquitous Internet of Things in the power grid construction stage, has improved the technical level of design, review, construction, and operation. As a substation of a power hub, there are thousands of internal lights and cables, and the path is intricate [3].

Under the traditional design mode, the cable laying of the substation needs to be laid manually according to the cable inventory, and manual statistics are required, which is time-consuming, labor-intensive and prone to deviations. In the current three-dimensional design mode, cable laying can only realize automatic statistics of cable length, and cannot generate a three-dimensional cable model in a specified arrangement order. Design data is difficult to reflect the spatial relationship of the entire station cable.

During construction, the cable installation position is deviated from the design intent, which often leads to excessive cable laying and uncontrollable progress in construction quality. Operation and maintenance personnel cannot obtain cable spatial location information. Facing the massive amount of cables in the station, accurately locating the required cables is like "finding a needle in a haystack."

The lack of basic cable data has a clear gap with the requirements for the construction of the ubiquitous power Internet of Things. Only innovative design techniques can realize the intelligent cable laying, high- quality construction, and refined operation and maintenance.

For the cable laying under the three-dimensional design of the substation, we must first accurately establish a cable trench model that conforms to the actual project. After installing the appropriate cable support in the trench, clearly include the cable layering and dividing principle and the cable layout in 1 According to the rules, the cable path and the cable start and end points are defined in the three-dimensional scene, and the cable length can be automatically counted after the cable inventory is imported. At the same time, the actual three-dimensional cable model can be generated in the cable trench according to the arrangement requirements.

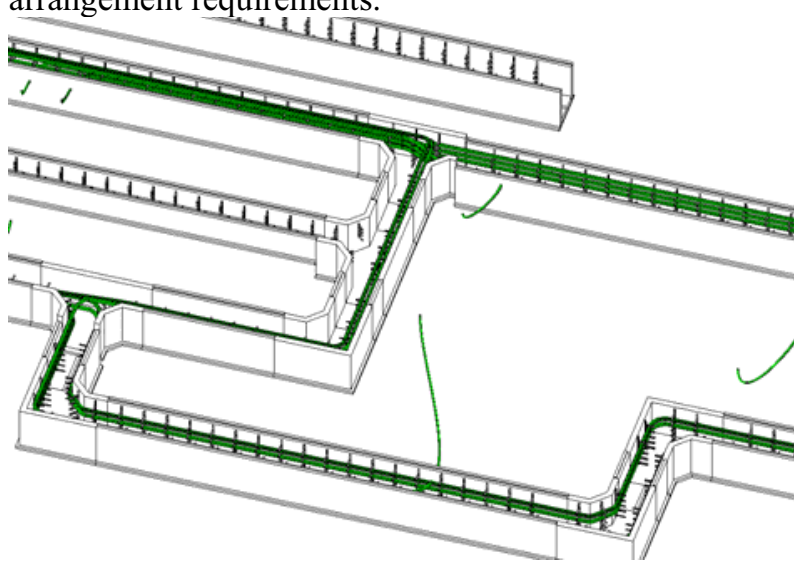

Fig. 1. 3D simulation diagram of cable laying.

Realize the rational arrangement and visual presentation of cable laying through key technical means such as automatic cable arrangement, automatic cross avoidance, and large-scale cable three-dimensional display. The 3D cable model has the characteristics of being viewable, editable, searchable and traceable [4].

\subsection{Construction assistance}

Construction assistance is based on the digital transfer of cable design data, by entering basic data, setting the construction plan, and accurately guiding the cable installation according to the generated three-dimensional cable arrangement model. Through the management of construction basic data such as construction personnel information and authority, cable inventory, installation material library, construction area and room information, system data support is realized.

Setting up a construction plan means setting up a construction package and a construction area, and allocating the existing laying workload according to area and sequence to achieve the purpose of orderly construction.

Through the terminal equipment, the construction personnel can not only intuitively see the overall cable layout effect and the actual situation of the cable bends, but also view the cable attribute information including the start and end points, model, and length in the threedimensional scene, which is convenient for cable installation and construction. 


\subsection{Cable fire protection design}

Cable fire protection design is the intelligent design of cable fire blocking and fire protection configuration in pipe trenches, screen cabinets, etc. in the substation.

Automatically generate and count cable fire protection materials through parameterized settings, call built-in fire protection schemes, configure sensors and automatic fire extinguishing devices, and communicate with the fire alarm system in the station to complete the transition from passive early warning, post-fire extinguishing to active early-warning and pre-fire protection in substations, To realize the intelligent design of cable fire protection.

\subsection{Engineering Applications}

Cable laying for a new $220 \mathrm{kV}$ substation in Shanxi. The substation is an outdoor GIS station, the main transformer scale is $3 \times 240 \mathrm{MVA}, 220 \mathrm{kV}$ outgoing line 8 times, $110 \mathrm{kV}$ outgoing line 14 times, $35 \mathrm{kV}$ outgoing line 12 times. Each main transformer is equipped with $4 \times 10$ MVar reactive power compensation device. All professional designers cooperated to complete the modeling of the cable trench in the station in the civil engineering major, and after the electrical major provided the total station optical cable inventory, the three-dimensional cable laying design was started [5].

First, import the required materials into the engineering database and install the cable support according to the size of the cable trench; the second step is to set up the laying methods of various cables, such as the $35 \mathrm{kV}$ high-voltage power cable demand-shaped layout, the cable spacing is controlled to twice the cable diameter, etc., and set at the same time The statistical margin of the cable quantity; the third step is to set the drawing style of the cable laying, including the path number and the cable label, etc.; the fourth step is to import the cable inventory, and the inventory includes the cable start and end equipment, cable specifications and models, etc.; the fifth step is for the cable Laying the wiring, mainly connecting the parts that the system cannot automatically identify such as the entrance and exit of the room, the interface with the buried pipe, and the height offset of the start and end devices, and identify the cable path; the sixth step is to set the cable laying rules and define the sequence of cable laying, Whether to lay according to the cable type, whether to limit the cable flow, whether to limit the volume ratio of the bracket and the cable trench, etc.; finally generate a visual three-dimensional model of the cables arranged in order.

Table 1. Cable laying equipment and materials for a substation.

\begin{tabular}{|c|c|c|c|}
\hline Name & $\begin{array}{c}\text { Specifications and } \\
\text { technical data }\end{array}$ & Unit & Quantity \\
\hline power cable & $\begin{array}{c}\text { ZC-YJV-26/35- } \\
1 \times 300\end{array}$ & $\mathrm{M}$ & 330 \\
\hline $\begin{array}{c}\text { ZC-YJV-26/35- } \\
1 \times 300\end{array}$ & $\mathrm{M}$ & 1995 \\
\hline $\begin{array}{c}\text { Sheath protection } \\
\text { box connecting } \\
\text { cable }\end{array}$ & YJV-10kV-1×120 & $\mathrm{M}$ & 240 \\
\hline
\end{tabular}

\begin{tabular}{|c|c|c|c|}
\hline Name & $\begin{array}{l}\text { Specifications and } \\
\text { technical data }\end{array}$ & Unit & Quantity \\
\hline \begin{tabular}{|c|} 
380V station \\
power supply cable
\end{tabular} & $\begin{array}{c}\text { ZC-YJV22-1kV- } \\
4 \times 150\end{array}$ & M & 525 \\
\hline \multirow[t]{9}{*}{$\begin{array}{c}380 \mathrm{~V} \text { station } \\
\text { power feeder cable }\end{array}$} & $\begin{array}{c}\text { ZC-YJV22-1kV- } \\
4 \times 240\end{array}$ & M & 170 \\
\hline & ZC-VV22-2×10 & $\mathrm{M}$ & 90 \\
\hline & $\begin{array}{l}\text { ZC-VV22- } \\
3 \times 10+1 \times 6\end{array}$ & $\mathrm{M}$ & 170 \\
\hline & ZC-YJV22-4×25 & M & 375 \\
\hline & ZC-YJV22-4×35 & $\mathrm{M}$ & 1675 \\
\hline & ZC-YJV22-4×70 & $\mathrm{M}$ & 110 \\
\hline & ZC-YJV22-4×150 & $\mathrm{M}$ & 35 \\
\hline & ZC-YJV22-2x50 & $\mathrm{M}$ & 35 \\
\hline & ZC-VV22-2×25 & $\mathrm{M}$ & 20 \\
\hline \multirow[t]{3}{*}{ Slot box } & $100 \times 200$ & $\mathrm{M}$ & 370 \\
\hline & $150 \times 250$ & $\mathrm{M}$ & 420 \\
\hline & $150 \times 400$ & $\mathrm{M}$ & 285 \\
\hline Cable fire barrier & $1000 \times 5$ & $\mathrm{M}$ & 385 \\
\hline \begin{tabular}{|c|} 
Fireproof \\
expansion module \\
\end{tabular} & XPM & & 15 \\
\hline $\begin{array}{l}\text { Refractory } \\
\text { partition }\end{array}$ & $10 \mathrm{~mm}$ & & 85 \\
\hline $\begin{array}{l}\text { Fire-retardant } \\
\text { coating }\end{array}$ & DFT-1 & $\mathrm{Kg}$ & 300 \\
\hline $\begin{array}{c}\text { Organic blocking } \\
\text { material }\end{array}$ & YHD-1 & $\mathrm{Kg}$ & 2500 \\
\hline
\end{tabular}

It can cut and mark any point of the cable trench, select any cable to view all its attribute information, and export the cable inventory to get the exact length of each cable.

\section{Selection of fireproof materials}

Fireproof materials must be qualified by the national technical appraisal, the products of the manufacturer and the production license issued by the public security department. In order to ensure product quality, the products on site must be sampled with fire resistance tests to ensure the safety of cable operation.

\section{Prevent other equipment from igniting the cable}

Oil-filled electrical equipment, coal conveying, pulverizing systems, and steam engine oil systems may cause the cable head to catch fire. When these equipment and systems break down and catch fire, the fire should not be allowed to burn nearby cables. For this reason, corresponding measures must be taken: first, the cable trench cover near the oil-filled electrical equipment should be sealed to prevent the oil from flowing to the cable trench when the equipment fails and catches fire. Ignite the cable; secondly, the dust accumulation on the cable near the coal conveying and pulverizing system should be cleaned regularly to prevent the spontaneous combustion of the pulverized coal from igniting the cable. The cable facing the explosion-proof door of the 
pulverizing system should be packed in a fireproof box to prevent Explosion-proof door action ignites the cable by spraying fire. The cables under the head of the steam turbine should be packed in a fire-proof trough box to prevent oil leakage from the steam engine oil system from entering the insulation material. The insulation material of the high-temperature pipeline must be covered with a metal sheath.

In addition, no flammable materials should be left in cable trenches, cable tunnels, and cable interlayers. The door of the cable interlayer must be locked to prevent people from entering and leaving at will to prevent the cable from catching fire due to human factors.

\section{Strengthen cable operation management}

When a fire breaks out in or near the cable trench, the doors or cable trench covers on both sides of the work site should be opened, warning signs should be set up, and fire extinguishers and fire-fighting sand should be provided. Disconnect the power when working, and divide the nearby cables with a slate. When using an open flame, keep a certain safe distance from the cable. After the work is completed, all holes should be sealed in time, and the adjacent doors should be closed or the cable trench cover should be covered. The cable channel should be kept clean and dry. It is strictly forbidden to pile up debris, and the dust on the cable and the cable rack should be cleaned frequently. Various brackets for fixing cables should be firm and free of rust. Check and record the operation of the cable regularly, and take timely measures when high temperature or overload is found. The cable head and insulating glue should be kept in good condition. The operating voltage should be stable and not exceed $15 \%$ of the rated voltage. The operating temperature and current carrying capacity of the cable in normal operation should meet the relevant requirements, and regular tests should be carried out in accordance with the regulations. Regularly inspect the cable lines to prevent damage to the cables by external forces, such as excavating and borrowing soil on the cable path, to improve the cable fire protection awareness of personnel at all levels. Strengthen the installation of fire-extinguishing devices and facilities, and install automatic fire alarm devices and effective fire-fighting devices in central control rooms, cable shafts and other locations. Such as fire doors, fire retardant sections, cable online monitoring systems, etc., fire doors and fire retardant sections can effectively isolate the cables, block the fire, suffocate the burning cables, and prevent the smoke from spreading. Avoid the spread of fire accidents. Through the cable online monitoring system, the occurrence of fire can be monitored in real time, the fire accident can be eliminated in the bud, and the occurrence and spread of fire accidents can be effectively prevented.

\section{Conclusions}

Only by clarifying the rules of cable fire accidents, constructing in strict accordance with design requirements and process standards, taking appropriate prevention measures and strengthening the scientific management of cable operation, can the occurrence of substation fire accidents be effectively avoided, the loss of life and property of personnel, and the guarantee Safe and stable operation of the power grid.

\section{Acknowledgments}

Authors wishing to acknowledge assistance and encouragement from colleagues, special work by technical staff.

\section{References}

1. Z. Yang. Technological innovation and application, 18, 212 (2014)

2. J. Chen. Enterprise Technology and Development, 2, 26(2013)

3. Y. Liu.Urban construction theory research (electronic version), 10, 98 (2011)

4. S. Zhai. China Power Enterprise Management, 20, 175(2016)

5. W. Shou. Electromechanical Information, 5, 27( 2010) 